\title{
Do Ophthalmology Residents Know How to Check the Calibration of a Goldmann Applanation Tonometer?
}

\author{
Aaron Carlisle ( $\square$ aaron294c@live.co.uk) \\ University of East Anglia Faculty of Medicine and Health Sciences
}

Sofia Habib

Norfolk and Norwich University Hospitals Eye Department

Zhiheng Lin

Norfolk and Norwich University Hospitals Eye Department

Jared Ching

Norfolk and Norwich University Hospitals Eye Department

Nuwan Niyadurupola

Norfolk and Norwich University Hospitals Eye Department

\section{Research Article}

Keywords: Goldmann, Applanation, Tonometer, Calibration, Residents

Posted Date: February 17th, 2022

DOI: https://doi.org/10.21203/rs.3.rs-1349552/v1

License: (c) (1) This work is licensed under a Creative Commons Attribution 4.0 International License. Read Full License 


\section{Abstract}

Purpose: A observational study to determine if ophthalmology residents know how to check Goldmann Applanation Tonometer (GAT) calibration.

Methods: The step-by-step technique for checking the calibration of a GAT was taken from the manufacturer's manual and developed into a mark sheet. Ophthalmology residents in years 2-8 of training from ten hospitals were individually observed and assessed checking calibration of a GAT. Participation was voluntary. Contact between participants was minimised to prevent communication about the study.

Results: 74\% ( $n=20)$ of eligible ophthalmology residents (years 2-8) from 10 hospitals (2 teaching hospitals and 8 local general hospitals) were observed checking GAT calibration. Only 45\% (n=9; Cl: 26$66 \%$ ) of ophthalmology residents were able to correctly check GAT calibration. Failure to mount the prism in the prism holder accounted for most cases of failure to correctly check GAT calibration.

Conclusions: Most ophthalmology residents were unable to correctly check GAT calibration. Although better than previously published results, this observational study shows that further training and assessment is required for ophthalmology residents to learn the technique of checking GAT calibration.

\section{Introduction}

Intraocular pressure (IOP) measurement is fundamental in the assessment of glaucoma since it is the only modifiable risk factor. Precise readings are paramount since large clinical trials have associated IOP thresholds with progression risk. The Early Manifest Glaucoma Trial showed that a reduction in IOP by $1 \mathrm{mmHg}$ led to a $10 \%$ reduction in progressive nerve damage [1]. The Goldmann applanation tonometer (GAT; Haag-Streit Diagnostics, Köniz, Switzerland) is the gold standard for IOP measurement and is used in most hospital eye services. However, it is subject to errors, of which calibration error is common, the most variable and often unnoticed [2].

A questionnaire survey showed that only $15 \%$ of ophthalmology residents in the UK checked GAT calibration in their current practice [3]. Another study revealed that less than $15 \%$ of ophthalmic practitioners knew how to check the calibration of a GAT [4]. This previous research has relied on selfreporting, with no published information on direct observation of skill.

The purpose of this novel observational study is to determine if ophthalmology residents know how to check GAT calibration by direct observation and assessment of this clinical skill.

\section{Methods}

Participants were recruited from ophthalmology residents in years 2-8 of training in the East of England (EoE) deanery, United Kingdom. The EoE deanery is comprised of 2 teaching hospitals and 11 local 
general hospitals [5]. The study gained favourable approval from the clinical audit department of Norfolk and Norwich University Hospital (Study number: OPH-15-16-13). Participants excluded from this study were: (i) consultants (ii) specialty and associate specialists (SAS) (iii) fellows (iv) ophthalmology residents in year 1 and (v) medical ophthalmologists.

All available ophthalmology residents (from years 2-8) on two days of assessment were recruited. Participation was voluntary. Ophthalmology residents were led to individual testing areas shielded from other participants and participants were asked to keep the study confidential. Informed consent was obtained. Ophthalmology residents were then asked to check GAT calibration. All necessary equipment was available and no confabulatory equipment was present. Multiple attempts were allowed, and no time limit was applied. Technique was assessed against a mark sheet. Criteria for checking GAT calibration were taken from the Haag-Streit Applanation Tonometer AT 900/870 Instructions for Use (Haag-Streit Diagnostics, Switzerland) [2]. The mark sheet assessed placement of the Goldmann prism to balance the instrument, correct calibration check at position 0 with or without the calibration rod and correct calibration check at position 2 and 6 with the calibration rod. Technique was recorded as correct if all steps were performed correctly and incorrect if any one step was performed incorrectly. Results were anonymised.

Participants were invited to respond to a Likert scale for the importance of the GAT calibration as a competency [6]. The Likert scale ranged from 1 to 5. (1: Not very important, 5: Very important).

This was a small observational study. The Adjusted Wald test was used to generate $95 \%$ confidence intervals. The Fisher's exact test was used to test statistical significance in the analysis of contingency tables. Statistical significance was determined at a $p<0.05$.

\section{Results}

Of the 27 eligible ophthalmology residents (years 2-8) within the EoE School of Ophthalmology, 20 (74\%) participated in the study. The remaining 7 ophthalmology residents were not available on the study days. Representation was from across all ophthalmology residents years 2-8 (Fig. 1). Participants were from the 2 teaching hospitals $(n=9), 8$ of the 11 local general hospitals $(n=8)$ or out of programme $(n=3)$.

Only $45 \%$ ( $n=9 ; 95 \% \mathrm{Cl}: 26-66 \%)$ of ophthalmology residents (years $2-8)$ were able to correctly check GAT calibration (Table 1). Of those participants who were able to correctly check GAT calibration most ( $n$ $=7)$ had a fluent technique with only a few $(n=2)$ using a trial-and-error type technique. Eleven ophthalmology residents (55\%) were unable to check GAT calibration. Of those participants who were unable to check GAT calibration, $100 \%(n=11)$ did not mount the prism in the prism holder. Four $(36 \%)$ of these participants who did not mount the prism in the prism holder were otherwise able to use the calibration rod to check calibration at the 0,2 and 6 positions. Seven (35\%) participants were unable to use the calibration rod and all seven participants also did not mount the prism correctly. Whilst most did not attempt to use the unfamiliar calibration rod $(n=4)$, some were observed placing the calibration rod in the prism holder $(n=2)$ or spinning the calibration rod around in its insert $(n=1)$. There was a tendency 
for a greater proportion of junior ophthalmology residents (years $2-4)(n=6 ; 55 \%)$ to be able to check GAT calibration correctly compared with senior ophthalmology residents (years $5-8)(n=3 ; 33 \%)$, however this did not reach statistical significance $(p=0.41)$.

Most ophthalmology residents (years $2-8)(n=14 ; 70 \%)$ recalled receiving teaching on how to check the calibration of a GAT (Table 2). Six (30\%) ophthalmology residents did not recall being taught how to check the calibration of a GAT. Of ophthalmology residents previously taught how to check calibration 7 (50\%) ophthalmology residents were observed as having a correct technique and 7 (50\%) ophthalmology residents were observed as having an incorrect technique. Of ophthalmology residents not previously taught how to check calibration $(n=6)$, only 2 ophthalmology residents $(33 \%)$ were observed as having a correct technique. Previous teaching of the technique appeared to increase the likelihood that the correct technique was used, however it did not reach statistical significance $(p=0.64)$. Since the main error with checking the calibration of a GAT related to failure to mount the prism in the prism holder, the association of prior teaching and correct use of the calibration rod was investigated. Ten (71\%) of the 14 ophthalmology residents who had received previous teaching were able to use the calibration rod correctly, compared with $4(67 \%)$ of the 6 ophthalmology residents who had no previous teaching $(p=$ 1.00).

Table 1

Technique for checking GAT calibration correctly and errors among participants by year of training.

\begin{tabular}{|lllll|}
\hline Technique & $\begin{array}{l}\text { Total, } \\
\mathbf{n = 2 0}\end{array}$ & $\begin{array}{l}\text { Resident Years 2-4, } \\
\mathbf{n = 1 1}\end{array}$ & $\begin{array}{l}\text { Resident Years 5- } \\
\mathbf{8 , n = 9}\end{array}$ & $\begin{array}{l}\text { P- } \\
\text { value }\end{array}$ \\
\hline Correct technique, $\mathbf{n}(\%)$ & $\mathbf{9 ( 4 5 )}$ & $\mathbf{6 ( 5 5 )}$ & $\mathbf{3 ( 3 3 )}$ & 0.41 \\
\hline $\begin{array}{l}\text { Incorrect technique, } \mathbf{n}(\%) \\
\begin{array}{l}\text { - Only failure to mount prism, } \mathrm{n} \\
(\%)\end{array}\end{array}$ & $\mathbf{1 1 ( 5 5 )}$ & $\mathbf{5 ( 4 5 )}$ & $\mathbf{6 ( 7 7 )}$ \\
$\begin{array}{l}\text { - Only improper calibration rod } \\
\text { use, } \mathrm{n}(\%)\end{array}$ & $0(0)$ & $0(0)$ & $2(33)$ \\
$\begin{array}{l}\text { - Both prism and calibration rod } \\
\text { errors, } \mathrm{n}(\%)\end{array}$ & $7(64)$ & $3(60)$ & $0(0)$ \\
\hline
\end{tabular}

In this study, only $50 \%$ of ophthalmology residents (years $2-8)(n=10)$ recalled previously being assessed on how to check the calibration of a GAT (Table 3). Of the 10 ophthalmology residents that had been assessed, $6(60 \%)$ ophthalmology residents were able to correctly check GAT calibration. In comparison, only $3(30 \%)$ ophthalmology residents that had not been assessed were able to check GAT calibration correctly $(p=0.37)$. When allowing for failure to balance the instrument with the prism in the prism mount, 8 (80\%) ophthalmology residents that had been previously assessed were able to use the calibration rod correctly, compared with $6(60 \%)$ ophthalmology residents that had not previously been assessed $(p=0.63)$. Of the ophthalmology residents who were previously assessed on this competency all stated this had occurred during year 1 or year 2 of ophthalmology training. Most ophthalmology residents stated that assessment of the technique of checking GAT calibration had taken place during 
their general ophthalmology placement $(n=4 ; 40 \%)$ or glaucoma placement $(n=3 ; 30 \%)$ and $3(30 \%)$ ophthalmology residents could not remember when.

Table 2

Technique for checking GAT calibration correctly and errors among assessed participants.

\begin{tabular}{|llll|}
\hline Technique & $\begin{array}{l}\text { Previously taught, } \mathbf{n} \\
=14\end{array}$ & $\begin{array}{l}\text { No prior teaching, } \\
\mathbf{n = 6}\end{array}$ & $\begin{array}{l}\text { P- } \\
\text { value }\end{array}$ \\
\hline Correct technique, $\mathrm{n}(\%)$ & $\mathbf{7 ( 5 0 )}$ & $\mathbf{2 ( 3 3 )}$ & 0.64 \\
\hline $\begin{array}{l}\text { Incorrect technique, } \mathrm{n}(\%) \\
\text { - Only failure to mount prism, } \mathrm{n}(\%)\end{array}$ & $3(\mathbf{5 0})$ & $\mathbf{4 ( 6 7 )}$ & \\
$\begin{array}{l}\text { - Only improper calibration rod use, } \mathrm{n} \\
(\%)\end{array}$ & $0(0)$ & $2(50)$ & \\
$\begin{array}{l}\text { - Both prism and calibration rod } \\
\text { errors, } \mathrm{n}(\%)\end{array}$ & $4(57)$ & $0(0)$ & \\
\hline
\end{tabular}

Most participants $(n=18 ; 90 \%)$ responded to a Likert scale for the importance of this competency. The mean score was 4.5. This indicated they felt it was important-to-very important.

\section{Table 3}

Technique for checking GAT calibration correctly and errors among assessed participants.

\begin{tabular}{|llll|}
\hline Technique & $\begin{array}{l}\text { Previously assessed, } \\
\mathrm{n}=10\end{array}$ & $\begin{array}{l}\text { No prior assessment, } \\
\mathrm{n}=10\end{array}$ & $\begin{array}{l}\text { P- } \\
\text { value }\end{array}$ \\
\hline Correct technique, $\mathrm{n}(\%)$ & $\mathbf{6 ( 6 0 )}$ & $\mathbf{3 ( 3 0 )}$ & 0.37 \\
\hline Incorrect technique, $\mathrm{n}(\%)$ & $\mathbf{4 ( 4 0 )}$ & $\mathbf{7 ( 7 0 )}$ \\
$-\quad$ Only failure to mount prism, $\mathrm{n}(\%)$ & $2(50)$ & $3(43)$ \\
$-\quad$ Only improper calibration rod use, & $0(0)$ & $0(0)$ \\
$\mathrm{n}(\%)$ & $2(50)$ & $4(57)$ \\
$-\quad \begin{array}{l}\text { Both prism and calibration rod } \\
\text { errors, } \mathrm{n}(\%)\end{array}$ & & \\
\hline
\end{tabular}

\section{Discussion}

To our knowledge, this is the first study to directly observe if ophthalmology residents were able to check GAT calibration and most (55\%) were unable to correctly do so. However, a greater proportion of participants (45\%) in our study were able to check GAT calibration compared with $15 \%$ reported in other studies [3-4]. It is important to note that previous published studies relied on self-reporting of this skill and not on direct observation of the skill. The authors of this study propose our participants performed comparatively well due to the good coverage of teaching of this practical skill in this region. Allowing for 
failure to balance the instrument by mounting the prism in the prism mount we found that $13(65 \%)$ ophthalmology residents were able to use the calibration rod correctly.

There was good participation of ophthalmology residents from the region and each of the training grades had good representation, reflecting the numbers of residents at each stage of training within the deanery. There was a trend for junior ophthalmology residents (years 2-4) to be able to check GAT calibration more successfully than senior residents (years 5-8), however this did not reach statistical significance. Most ophthalmology residents recalled being taught this practical skill in years 1 or 2 of training. It is possible that junior ophthalmology residents appeared to be more successful in checking GAT calibration since they had received teaching and undergone assessment of this competency relatively recently. Additionally, it is possible that the time lapse since senior ophthalmology residents were taught and assessed this competency may have contributed to this skill being lost.

The most common error identified with checking the calibration of the GAT was failure to balance the instrument by mounting the prism in the prism holder. It may be that this part of checking GAT calibration is not emphasised as important or is easily forgotten. Observation of this practical skill in the present study was not performed in a clinical setting where it may have been more intuitive for the ophthalmology resident to mount the prism in the prism holder.

Having been taught the skill of GAT calibration appeared to increase the likelihood of ophthalmology residents being able to correctly check the calibration of a GAT (50\%) compared with those that had not been previously taught (33\%), but this did not reach statistical significance. Similarly, having been taught GAT calibration seemed to increase the likelihood of being able to use the calibration rod correctly $(71 \%)$ compared with those that had not been taught (67\%). Having been assessed on GAT calibration during their training appeared to increase both the ability to check GAT calibration correctly (60\% previously assessed group vs $30 \%$ not previously assessed group) and ability to use the calibration rod correctly ( $80 \%$ previously assessed group vs $60 \%$ not previously assessed group) but this did not reach statistical significance.

Ophthalmology residents participating in this study identified being able to check GAT calibration as an important practical skill to learn. Previous small studies by other groups have shown that $18-100 \%$ of GATs within units are uncalibrated [3-4, 7-10]. Furthermore, a survey of all hospital eye services in the UK revealed $39 \%$ of GATs were never checked or were not regularly checked in an identifiable pattern [3, 11]. To ensure accurate IOP readings the manufacturer Haag Streit recommend that the calibration of the tonometer is checked monthly and returned for recalibration if found to be faulty [2]. A multicentre study has suggested newer GATs ( $<1$ year old) could be checked twice yearly while older GATs should be checked monthly [12].

There are limitations to this study; most notably there was a small sample size, and it was performed within one deanery in the UK. Whilst a good proportion of ophthalmology residents participated, some of the smaller eye-units were not represented. Additionally, the study was performed in a non-clinical setting and performance may vary within a clinical setting. Participants were asked to not communicate with 
each other regarding the topic of the study, but they were not completely isolated from each other. Hence, prior knowledge of the study may have increased the success rate due to the participants revising the technique before participating in the study.

Checking the calibration of a GAT is of training significance and of clinical significance since using an uncalibrated GAT could lead to under- or over- estimation of IOP. Under-estimation of IOP has the possible consequences of delay in instigating appropriate interventions and could lead to progression of glaucoma. Over-estimation of IOP has the possible consequence of unnecessary intervention. The recommendations of this study are that ophthalmology residents should be trained in checking GAT calibration and supervisors should observe and assess this skill.

\section{Declarations}

\section{Acknowledgements}

We would like to thank Mr Narman Puvanachandra, Training Programme Director in the East of England.

\section{Funding}

This study has not been funded or sponsored.

\section{Competing Interests}

The authors declare no conflicts of interest.

\section{Ethics Approval}

The study gained favourable approval from the clinical audit department of Norfolk and Norwich University Hospital (Study number: OPH-15-16-13)

\section{References}

1. Leske MC, Heijl A, Hyman L, Bengtsson B (1999) Early Manifest Glaucoma Trial: design and baseline data. Ophthalmology 106(11):2144-2153. https://doi.org/10.1016/s0161-6420(99)90497-9

2. Haag-Streit Diagnostics. Instructions for Use: Applanation Tonometer: AT 900/870. Switzerland. Haag-Streit Diagnostics (2015) Available from: http://www.haag-streit.com/ product/tonometry/at900r/instructions-for-use-ifu-at-900r.html [Accessed on: 20/10/16]

3. Kumar N, Jivan S (2006) Goldmann applanation tonometer calibration error checks: current practice in the UK. Eye 21(6):733-734. https://doi.org/10.1038/sj.eye.6702316

4. Wessels I, Oh Y (1990) Tonometer Utilization, Accuracy, and Calibration Under Field Conditions. Arch Ophthalmol 108(12):1709. https://doi.org/10.1001/archopht.1990.01070140063030 
5. Welcome to East Of England Ophthalmology | East of England. [online] Available at: https://heeoe.hee.nhs.uk/ophthalmology/welcome-east-england-ophthalmology [Accessed 4 February 2021]

6. Joshi A, Kale S, Chandel et al (2015) Likert Scale: Explored and Explained. Br J Appl Sci Technol 396-403. https://doi.org/10.9734/BJAST/2015/14975

7. Choudhari NS, Ramavath S, Rekha G, Senthil S et al (2016) A Simplified (Screening) Approach to Check the Calibration Status of the Goldmann Applanation Tonometer. J Glaucoma 25(10):812-814. https://doi.org/10.1097/IJG.0000000000000426

8. Choudhari NS, Moorthy KP, Tungikar VB et al (2014) Rectifying calibration error of Goldmann applanation tonometer is easy! Indian J Ophthalmol 62(11):1082-1085.

https://doi.org/10.4103/0301-4738.146761

9. Choudhari NS, Jadhav V, George R et al (2011) Variability in the calibration error of the goldmann applanation tonometer. J Glaucoma 20(8):492-496.

https://doi.org/10.1097/IJG.0b013e3181f464b8

10. Choudhari NS, George R, Baskaran M et al (2009) Measurement of Goldmann applanation tonometer calibration error. Ophthalmology 116(1):3-8. https://doi.org/10.1016/j.ophtha.2008.06.020

11. Kumar N, Hillier RJ (2007) Goldmann tonometer calibration: a national survey. Eye 23(2):413-415. https://doi.org/10.1038/sj.eye.6703010

12. Choudhari NS, Rao HLm Ramavath S et al (2016) How often the goldmann applanation tonometer should be checked for calibration error? J Glaucoma 25(11):908-913. https://doi.org/10.1097/IJG.0000000000000545

\section{Figures}




\section{Recruitment Ophthalmic Trainees By Year Of Training}

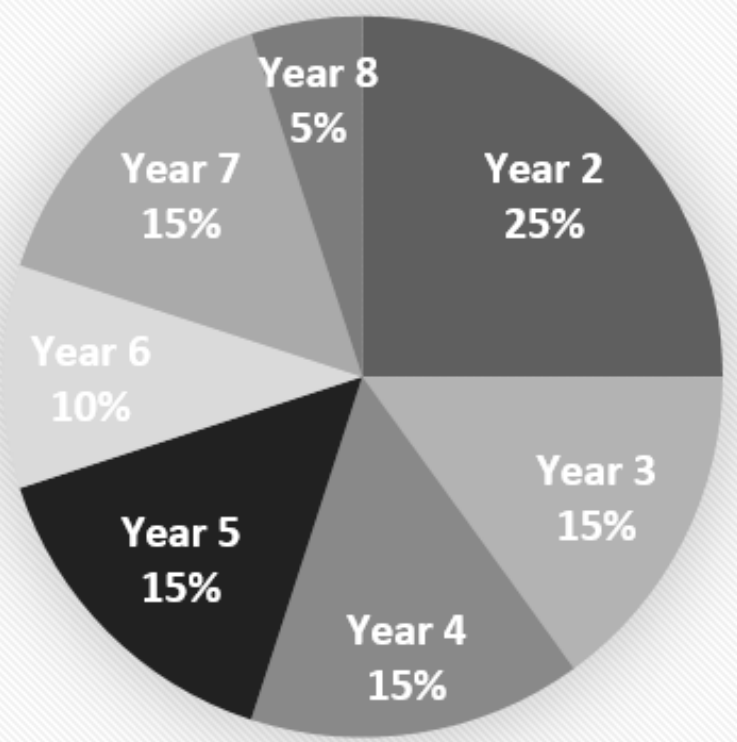

Figure 1

Representation of ophthalmology residents by year of training 